\title{
Invariant Means and Reversible Semigroup of Relatively Nonexpansive Mappings in Banach Spaces
}

\author{
Kyung Soo Kim \\ Graduate School of Education, Mathematics Education, Kyungnam University, Changwon 631-701, Republic of Korea \\ Correspondence should be addressed to Kyung Soo Kim; kksmj@kyungnam.ac.kr
}

Received 9 May 2014; Accepted 1 July 2014; Published 20 July 2014

Academic Editor: Jong Kyu Kim

Copyright (C) 2014 Kyung Soo Kim. This is an open access article distributed under the Creative Commons Attribution License, which permits unrestricted use, distribution, and reproduction in any medium, provided the original work is properly cited.

\begin{abstract}
The purpose of this paper is to study modified Halpern type and Ishikawa type iteration for a semigroup of relatively nonexpansive mappings $\mathfrak{I}=\{T(s): s \in S\}$ on a nonempty closed convex subset $C$ of a Banach space with respect to a sequence of asymptotically left invariant means $\left\{\mu_{n}\right\}$ defined on an appropriate invariant subspace of $l^{\infty}(S)$, where $S$ is a semigroup. We prove that, given some mild conditions, we can generate iterative sequences which converge strongly to a common element of the set of fixed points $F(\mathfrak{I})$, where $F(\mathfrak{J})=\bigcap\{F(T(s)): s \in S\}$.
\end{abstract}

\section{Introduction}

Let $E$ be a real Banach space with the topological dual $E^{*}$ and let $C$ be a closed and convex subset of $E$. A mapping $T$ of $C$ into itself is called nonexpansive if $\|T x-T y\| \leq\|x-y\|$ for each $x, y \in C$.

Three classical iteration processes are often used to approximate a fixed point of a nonexpansive mapping. The first one is introduced by Halpern [1] and is defined as follows:

$$
\begin{gathered}
x_{0}=u \in C, \quad \text { chosen arbitrarily, } \\
x_{n+1}=\alpha_{n} u+\left(1-\alpha_{n}\right) T x_{n}, \quad \forall n \geq 1,
\end{gathered}
$$

where $\left\{\alpha_{n}\right\}$ is a sequence in $[0,1]$. He pointed out that the conditions $\lim _{n \rightarrow \infty} \alpha_{n}=0$ and $\sum_{n=1}^{\infty} \alpha_{n}=\infty$ are necessary in the sense that if the iteration (1) converges to a fixed point of $T$, then these conditions must be satisfied. The second iteration process is known as Mann's iteration process [2] which is defined as follows:

$$
x_{n+1}=\alpha_{n} x_{n}+\left(1-\alpha_{n}\right) T x_{n}, \quad \forall n \geq 1,
$$

where the initial $x_{1}$ is taken in $C$ arbitrary and the sequence $\left\{\alpha_{n}\right\}$ is in $[0,1]$.
The third iteration process is referred to as Ishikawa's iteration process [3] which is defined as follows:

$$
\begin{gathered}
y_{n}=\beta_{n} x_{n}+\left(1-\beta_{n}\right) T x_{n}, \\
x_{n+1}=\alpha_{n} x_{n}+\left(1-\alpha_{n}\right) T y_{n}, \quad \forall n \geq 1,
\end{gathered}
$$

where the initial $x_{1}$ is taken in $C$ arbitrary and $\left\{\alpha_{n}\right\}$ and $\left\{\beta_{n}\right\}$ are sequences in $[0,1]$.

In 2007, Lau et al. [4] proposed the following modification of Halpern's iteration (1) for amenable semigroups of nonexpansive mappings in a Banach space.

Theorem 1. Let $S$ be a left reversible semigroup and let $\mathfrak{I}=$ $\{T(s): s \in S\}$ be a representation of $S$ as nonexpansive mappings from a compact convex subset $C$ of a strictly convex and smooth Banach space $E$ into $C$, let $X$ be an amenable and $\Im$-stable subspace of $l^{\infty}(S)$, and let $\left\{\mu_{n}\right\}$ be a strongly left regular sequence of means on $X$. Let $\left\{\alpha_{n}\right\}$ be a sequence in $[0,1]$ such that $\lim _{n \rightarrow \infty} \alpha_{n}=0$ and $\sum_{n=1}^{\infty} \alpha_{n}=\infty$. Let $x_{1}=x \in C$ and let $\left\{x_{n}\right\}$ be the sequence defined by

$$
x_{n+1}=\alpha_{n} x+\left(1-\alpha_{n}\right) T\left(\mu_{n}\right) x_{n}, \quad n \geq 2 .
$$

Then $\left\{x_{n}\right\}$ converges strongly to $P x$, where $P$ denotes the unique sunny nonexpansive retraction of $C$ onto $F(\mathfrak{I})$.

Let $C$ be a closed and convex subset of $E$ and let $T$ be a mapping from $C$ into itself. We denote by $F(T)$ the set of fixed 
points of $T$. Point $p$ in $C$ is said to be an asymptotic fixed point of $T$ [5] if $C$ contains a sequence $\left\{x_{n}\right\}$ which converges weakly to $p$ such that the strong $\lim _{n \rightarrow \infty}\left(T x_{n}-x_{n}\right)=0$. The set of asymptotic fixed points of $T$ will be denoted by $\widehat{F}(T)$. A mapping $T$ from $C$ into itself is called relatively nonexpansive [6-8], if $\widehat{F}(T)=F(T)$ and $\phi(p, T x) \leq \phi(p, x)$ for all $x \in C$ and $p \in F(T)$. The asymptotic behavior of relatively nonexpansive mappings was studied in $[6,7,9]$.

Recently, Kim [10] proved a strong convergence theorem for relatively nonexpansive mappings in a Banach space by using the shrinking method.

Theorem 2. Let $S$ be a left reversible semigroup and let $\mathfrak{\Im}=$ $\{T(s): s \in S\}$ be a representation of S as relatively nonexpansive mappings from a nonempty, closed, and convex subset $C$ of a uniformly convex and uniformly smooth Banach space E into $C$ with $F(\mathfrak{\Im}) \neq \emptyset$. Let $X$ be a subspace of $l^{\infty}(S)$ and let $\left\{\mu_{n}\right\}$ be a asymptotically left invariant sequence of means on $X$. Let $\left\{\alpha_{n}\right\}$ be a sequence in $[0,1]$ such that $0<\alpha_{n}<1$ and $\lim _{n \rightarrow \infty} \alpha_{n}=$ 0 . Let $\left\{x_{n}\right\}$ be a sequence generated by the following algorithm:

$$
\begin{gathered}
x_{0} \in C, \quad \text { chosen arbitrarily, } \\
C_{1}=C, \\
x_{1}=\Pi_{C_{1}} x_{0}, \\
y_{n}=J^{-1}\left(\alpha_{n} J x_{1}+\left(1-\alpha_{n}\right) J T_{\mu_{n}} x_{n}\right), \\
\phi\left(z \in C_{n}:\right. \\
x_{n+1}=\prod_{C_{n+1}} x_{1}, \quad \forall n \geq 1 .
\end{gathered}
$$

Then $\left\{x_{n}\right\}$ converges strongly to $\Pi_{F(\Im)} x_{1}$, where $\Pi_{F(\Im)}$ is the generalized projection from $C$ onto $F(\Im)$.

Let $S$ be a semigroup. The purpose of this paper is to study modified Halpern type and Ishikawa type iterations for a semigroup of relatively nonexpansive mappings $\mathfrak{I}=$ $\{T(s): s \in S\}$ on a nonempty closed convex subset $C$ of a Banach space with respect to a sequence of asymptotically left invariant means $\left\{\mu_{n}\right\}$ defined on an appropriate invariant subspace of $l^{\infty}(S)$. We prove that, given some mild conditions, we can generate iterative sequences which converge strongly to a common element of the set of fixed points $F(\mathfrak{I})$, where $F(\mathfrak{\Im})=\bigcap\{F(T(s)): s \in S\}$.

\section{Preliminaries}

A real Banach space $E$ is said to be strictly convex if $\|(x+$ $y) / 2 \|<1$ for all $x, y \in E$ with $\|x\|=\|y\|=1$ and $x \neq y$. It is said to be uniformly convex if $\lim _{n \rightarrow \infty}\left\|x_{n}-y_{n}\right\|=0$ for any two sequences $\left\{x_{n}\right\}$ and $\left\{y_{n}\right\}$ in $E$ such that $\left\|x_{n}\right\|=\left\|y_{n}\right\|=1$ and $\lim _{n \rightarrow \infty}\left\|\left(x_{n}+y_{n}\right) / 2\right\|=1$. Let $U=\{x \in E:\|x\|=1\}$ be the unit sphere of $E$. Then the Banach space $E$ is said to be smooth if

$$
\lim _{t \rightarrow 0} \frac{\|x+t y\|-\|x\|}{t}
$$

exists for each $x, y \in U$. It is said to be uniformly smooth if the limit is attained uniformly for $x, y \in E$.

Let $E$ be a real Banach space with norm $\|\cdot\|$ and let $E^{*}$ be the dual space of $E$. Denote by $\langle\cdot, \cdot\rangle$ the duality product. We denote by $J$ the normalized duality mapping from $E$ to $2^{E^{*}}$ defined by

$$
J x=\left\{f^{*} \in E^{*}:\left\langle x, f^{*}\right\rangle=\|x\|^{2}=\left\|f^{*}\right\|^{2}\right\},
$$

for $x \in E$. A Banach space $E$ is said to have the Kadec-Klee property if a sequence $\left\{x_{n}\right\}$ of $E$ satisfies that $x_{n} \rightarrow x$ and $\left\|x_{n}\right\| \rightarrow\|x\|$ and then $x_{n} \rightarrow x$, where $\rightarrow$ and $\rightarrow$ denote the weak convergence and the strong convergence, respectively.

We know the following:

(1) the duality mapping $J$ is monotone, that is, $\left\langle x-y, x^{*}-\right.$ $\left.y^{*}\right\rangle \geq 0$ whenever $x^{*} \in J x$ and $y^{*} \in J y$;

(2) if $E$ is strictly convex, then $J$ is one-to-one; that is, if $J x \cap J y$ is nonempty, then $x=y$;

(3) if $E$ is strictly convex, then $J$ is strictly monotone; that is, $x=y$ whenever $\left\langle x-y, x^{*}-y^{*}\right\rangle=0, x^{*} \in J x$ and $y^{*} \in J y$;

(4) if $E$ is uniformly convex, then $E$ has the Kadec-Klee property;

(5) if $E$ is uniformly convex, then $E$ is reflexive and strictly convex;

(6) if $E$ is smooth, then $J$ is single-valued and norm-toweak $^{*}$ continuous;

(7) if $E$ is uniformly smooth, then $J$ is uniformly normto-norm continuous on bounded subsets of $E$;

(8) if $E$ is reflexive, then $J$ is onto;

(9) if $E$ is smooth and reflexive, then $J$ is norm-to-weak continuous; that is, $J x_{n} \rightarrow J x$ whenever $x_{n} \rightarrow x$;

(10) if $E$ is smooth, strictly convex, and reflexive, then $J$ is single-valued, one-to-one and onto; in this case, the inverse mapping $J^{-1}$ coincides with the duality mapping on $E$;

(11) if $E^{*}$ is strictly convex, then $J$ is single-valued;

(12) the norm of $E^{*}$ is Fréchet differentiable if and only if $E$ is strictly convex and reflexive Banach space which has the Kadec-Klee property.

For more details, see [11].

As well known, if $C$ is a nonempty, closed, and convex subset of a Hilbert space $H$ and $P_{C}: H \rightarrow C$ is the metric projection of $H$ onto $C$, then $P_{C}$ is nonexpansive (see, the reference therein). This fact actually characterizes Hilbert spaces. Consequently, it is not true to more general Banach spaces. In this connection, Alber [12] introduced a generalized projection operator $\Pi_{C}$ in a Banach space $E$ which is an analogue of the metric projection in Hilbert spaces. Consider the function defined by

$$
\phi(x, y)=\|x\|^{2}-2\langle x, J y\rangle+\|y\|^{2}
$$


for $x, y \in E$. Observe that, in a Hilbert space $H$, (8) reduces to

$$
\phi(x, y)=\|x-y\|^{2}
$$

for $x, y \in H$. The generalized projection $\Pi_{C}: E \rightarrow C$ is a mapping that assigns an arbitrary point $x \in E$ to the minimum point of the functional $\phi(x, y)$; that is, $\Pi_{C} x=\bar{x}$, where $\bar{x}$ is the solution to the minimization problem:

$$
\phi(\bar{x}, x)=\inf _{y \in C} \phi(y, x)
$$

The existence and uniqueness of the operator $\Pi_{C}$ follow from the properties of the functional $\phi(x, y)$ and strict monotonicity of the mapping $J$ (see, e.g., $[12,13]$ ). In a Hilbert space, $\Pi_{C}=P_{C}$. It is obvious from the definition of the function $\phi$ that

$\left(\phi_{1}\right)(\|x\|-\|y\|)^{2} \leq \phi(x, y) \leq(\|x\|+\|y\|)^{2}$ for all $x, y \in E$,

$\left(\phi_{2}\right) \phi(x, y)=\phi(x, z)+\phi(z, y)+2\langle x-z, J z-J y\rangle$ for all $x, y, z \in E$,

$\left(\phi_{3}\right) \phi(x, y)=\langle x, J x-J y\rangle+\langle y-x, J y\rangle \leq\|x\|\|J x-J y\|+$ $\|y-x\|\|y\|$ for all $x, y \in E$,

$\left(\phi_{4}\right)$ if $E$ is a reflexive, strictly convex, and smooth Banach space, then, for all $x, y \in E$,

$$
\phi(x, y)=0 \quad \text { iff } x=y .
$$

For more details see [14].

Let $S$ be a semigroup. We denote by $l^{\infty}(S)$ the Banach space of all bounded real-valued functionals on $S$ with supremum norm. For each $s \in S$, we define the left and right translation operators $l(s)$ and $r(s)$ on $l^{\infty}(S)$ by

$$
(l(s) f)(t)=f(s t), \quad(r(s) f)(t)=f(t s),
$$

for each $t \in S$ and $f \in l^{\infty}(S)$, respectively. Let $X$ be a subspace of $l^{\infty}(S)$ containing 1 . An element $\mu$ in the dual space $X^{*}$ of $X$ is said to be a mean on $X$ if $\|\mu\|=\mu(1)=1$. For $s \in S$, we can define a point evaluation $\delta_{s}$ by $\delta_{s}(f)=f(s)$ for each $f \in X$. It is well known that $\mu$ is mean on $X$ if and only if

$$
\inf _{s \in S} f(s) \leq \mu(f) \leq \sup _{s \in S} f(s)
$$

for each $f \in X$.

Let $X$ be a translation invariant subspace of $l^{\infty}(S)$ (i.e., $l(s) X \subset X$ and $r(s) X \subset X$ for each $s \in S)$ containing 1 . Then a mean $\mu$ on $X$ is said to be left invariant (resp., right invariant) if

$$
\mu(l(s) f)=\mu(f), \quad(\text { resp., } \mu(r(s) f)=\mu(f))
$$

for each $s \in S$ and $f \in X$. A mean $\mu$ on $X$ is said to be invariant if $\mu$ is both left and right invariant [15-19]. $X$ is said to be left (resp., right) amenable if $X$ has a left (resp., right) invariant mean. $X$ is amenable if $X$ is left and right amenable. We call a semigroup $S$ amenable if $X$ is amenable. Further, amenable semigroups include all commutative semigroups and solvable groups. However, the free group or semigroup of two generators is not left or right amenable (see [20-22]).

A net $\left\{\mu_{\alpha}\right\}$ of means on $X$ is said to be asymptotically left (resp., right) invariant if

$$
\begin{gathered}
\lim _{\alpha}\left(\mu_{\alpha}(l(s) f)-\mu_{\alpha}(f)\right)=0, \\
\left(\text { resp., } \lim _{\alpha}\left(\mu_{\alpha}(r(s) f)-\mu_{\alpha}(f)\right)=0\right),
\end{gathered}
$$

for each $f \in X$ and $s \in S$, and it is said to be left (resp., right) strongly asymptotically invariant (or strong regular) if

$$
\begin{gathered}
\lim _{\alpha}\left\|l^{*}(s) \mu_{\alpha}-\mu_{\alpha}\right\|=0, \\
\text { (resp., } \left.\lim _{\alpha}\left\|r^{*}(s) \mu_{\alpha}-\mu_{\alpha}\right\|=0\right),
\end{gathered}
$$

for each $s \in S$, where $l^{*}(s)$ and $r^{*}(s)$ are the adjoint operators of $l(s)$ and $r(s)$, respectively. Such nets were first studied by Day in [20] where they were called weak ${ }^{*}$ invariant and norm invariant, respectively.

It is easy to see that if a semigroup $S$ is left (resp., right) amenable, then the semigroup $S^{\prime}=S \cup\{e\}$, where $e s^{\prime}=$ $s^{\prime} e=s^{\prime}$ for all $s^{\prime} \in S$, is also left (resp., right) amenable and converse.

From now on $S$ denotes a semigroup with an identity e. $S$ is called left reversible if any two right ideals of $S$ have nonvoid intersection; that is, $a S \cap b S \neq \emptyset$ for $a, b \in S$. In this case, $(S, \preceq)$ is a directed system when the binary relation " $\preceq$ " on $S$ is defined by $a \preceq b$ if and only if $\{a\} \cup a S \supseteq\{b\} \cup b S$ for $a, b \in S$. It is easy to see that $t \preceq t s$ for all $t, s \in S$. Further, if $t \preceq s$ then $p t \preceq p s$ for all $p \in S$. The class of left reversible semigroup includes all groups and commutative semigroups. If a semigroup $S$ is left amenable, then $S$ is left reversible. But the converse is not true [23-28].

Let $S$ be a semigroup and let $C$ be a closed and convex subset of $E$. Let $F(T)$ denote the fixed point set of $T$. Then $\mathfrak{I}=\{T(s): s \in S\}$ is called a representation of $S$ as relatively nonexpansive mappings on $C$ if $T(s)$ is relatively nonexpansive with $T(e)=I$ and $T(s t)=T(s) T(t)$ for each $s, t \in S$. We denote by $F(\mathfrak{I})$ the set of common fixed points of $\{T(s): s \in$ $S\}$; that is,

$$
F(\Im)=\bigcap_{s \in S} F(T(s))=\bigcap_{s \in S}\{x \in C: T(s) x=x\} .
$$

We know that if $\mu$ is a mean on $X$ and if for each $x^{*} \in E^{*}$ the function $s \mapsto\left\langle T(s) x, x^{*}\right\rangle$ is contained in $X$ and $C$ is weakly compact, then there exists a unique point $x_{0}$ of $E$ such that $\mu\left\langle T(\cdot) x, x^{*}\right\rangle=\left\langle x_{0}, x^{*}\right\rangle$ for each $x^{*} \in E^{*}$. We denote such a point $x_{0}$ by $T_{\mu} x$. Note that $T_{\mu} x$ is contained in the closure of the convex hull of $\{T(s) x: s \in S\}$ for each $x \in C$. Note that $T_{\mu} z=z$ for each $z \in F(\Im)$; see [29-31].

\section{Lemmas}

We need the following lemmas for the proof of our main results.

Lemma 3 (see [9]). Let $E$ be a strictly convex and smooth Banach space, let $C$ be a closed convex subset of $E$, and let $T$ 
be a relatively nonexpansive mapping from $C$ into itself. Then $F(T)$ is closed and convex.

Lemma 4 (see $[12,32]$ ). Let $E$ be a reflexive, strictly convex, and smooth Banach space and let $C$ be a nonempty, closed, and convex subset of $E$ and $x \in E$. Then

$$
\phi\left(y, \Pi_{C} x\right)+\phi\left(\Pi_{C} x, x\right) \leq \phi(y, x),
$$

for all $y \in C$.

Lemma 5 (see [32]). Let E be a uniformly convex and smooth Banach space and let $\left\{x_{n}\right\},\left\{y_{n}\right\}$ be two sequences of $E$. If $\lim _{n \rightarrow \infty} \phi\left(x_{n}, y_{n}\right)=0$ and either $\left\{x_{n}\right\}$ or $\left\{y_{n}\right\}$ is bounded, then $\lim _{n \rightarrow \infty}\left\|x_{n}-y_{n}\right\|=0$.

Lemma 6 (see $[4,33])$. Let $\mu$ be a left invariant mean on $X$. Then $F(\mathfrak{I})=F\left(T_{\mu}\right) \cap C_{a}$, where $C_{a}$ denotes the set of almost periodic elements in $C$; that is, all $x \in C$ such that $\{T(s) x: s \in$ $S\}$ is relatively compact in the norm topology of $E$.

Lemma 7 (cf. $[4,10])$. Let $\left\{\mu_{n}\right\}$ be an asymptotically left invariant sequence of means on $X$. If $z \in C_{a}$ and $\liminf _{n \rightarrow \infty} \| T_{\mu_{n}} z-$ $z \|=0$, then $z$ is a common fixed point of $\mathfrak{I}$.

\section{Strong Convergence Theorems}

In this section, we will establish two strong convergence theorems of various iterative sequences for finding common fixed point of relatively nonexpansive mappings in a uniformly convex and uniformly smooth Banach spaces (cf. [34-36]).

We begin with a strong convergence theorem of modified Halpern's type.

Theorem 8. Let $S$ be a left reversible semigroup and let $\mathfrak{\Im}=$ $\{T(s): s \in S\}$ be a representation of $S$ as relatively nonexpansive mappings from a nonempty, closed, and convex subset $C$ of a uniformly convex and uniformly smooth Banach space $E$ into itself. Let $X$ be a subspace of $l^{\infty}(S)$ and let $\left\{\mu_{n}\right\}$ be an asymptotically left invariant sequence of means on X. Let $\left\{\alpha_{n}\right\}$ be a sequence in $(0,1)$ such that $\lim _{n \rightarrow \infty} \alpha_{n}=0$. Let $\left\{x_{n}\right\}$ be a sequence generated by the following algorithm:

$$
\begin{gathered}
x_{0} \in C, \quad \text { chosen arbitrarily, } \\
x_{n+1}=\Pi_{C} J^{-1}\left(\alpha_{n} J x_{0}+\left(1-\alpha_{n}\right) J T_{\mu_{n}} x_{n}\right), \quad \forall n \geq 0 .
\end{gathered}
$$

If the interior of $F(\mathfrak{I})$ is nonempty, then $\left\{x_{n}\right\}$ converges strongly to some common fixed point $F(\mathfrak{I})$.

Proof. We show first that the sequence $\left\{x_{n}\right\}$ converges strongly in $C$.

From Lemma 3, we know $F(T)$ is closed and convex. So, we can define the generalized projection $\Pi_{C}$ onto $F(\mathfrak{I})$. Most of all, we have

$$
\begin{aligned}
\left\|T_{\mu_{n}} x_{n}\right\| & =\sup \left\{\left|\left\langle T_{\mu_{n}} x_{n}, x^{*}\right\rangle\right|: x^{*} \in E^{*},\left\|x^{*}\right\|=1\right\} \\
& =\sup \left\{\left|\left(\mu_{n}\right)_{s}\left\langle T(s) x_{n}, x^{*}\right\rangle\right|: x^{*} \in E^{*},\left\|x^{*}\right\|=1\right\}
\end{aligned}
$$

$$
\begin{aligned}
& \leq \sup \left\{\left(\mu_{n}\right)_{s}\left(\left\|T(s) x_{n}\right\|\left\|x^{*}\right\|\right): x^{*} \in E^{*},\left\|x^{*}\right\|=1\right\} \\
& =\left(\mu_{n}\right)_{s}\left\|T(s) x_{n}\right\| .
\end{aligned}
$$

Then, from the definition of relatively nonexpansive, we have

$$
\begin{aligned}
\phi\left(u, T_{\mu_{n}} x_{n}\right)= & \|u\|^{2}-2\left\langle u, J T_{\mu_{n}} x_{n}\right\rangle+\left\|T_{\mu_{n}} x_{n}\right\|^{2} \\
= & \|u\|^{2}-2\left(\mu_{n}\right)_{s}\left\langle u, J T(s) x_{n}\right\rangle \\
& +\left(\mu_{n}\right)_{s}\left\|T(s) x_{n}\right\|^{2} \\
= & \left(\mu_{n}\right)_{s} \phi\left(u, T(s) x_{n}\right) \\
\leq & \left(\mu_{n}\right)_{s} \phi\left(u, x_{n}\right)=\phi\left(u, x_{n}\right),
\end{aligned}
$$

for all $u \in F(\Im)$. From the convexity of $\|\cdot\|^{2}$ and (21), we get

$$
\begin{aligned}
& \phi\left(u, x_{n+1}\right) \\
&= \phi\left(u, \Pi_{C} J^{-1}\left(\alpha_{n} J x_{0}+\left(1-\alpha_{n}\right) J T_{\mu_{n}} x_{n}\right)\right) \\
& \leq \phi\left(u, J^{-1}\left(\alpha_{n} J x_{0}+\left(1-\alpha_{n}\right) J T_{\mu_{n}} x_{n}\right)\right) \\
&=\|u\|^{2}-2\left\langle u, \alpha_{n} J x_{0}+\left(1-\alpha_{n}\right) J T_{\mu_{n}} x_{n}\right\rangle \\
&+\left\|\alpha_{n} J x_{0}+\left(1-\alpha_{n}\right) J T_{\mu_{n}} x_{n}\right\|^{2} \\
& \leq\|u\|^{2}-2 \alpha_{n}\left\langle u, J x_{0}\right\rangle-2\left(1-\alpha_{n}\right)\left\langle u, J T_{\mu_{n}} x_{n}\right\rangle \\
&+\alpha_{n}\left\|x_{0}\right\|^{2}+\left(1-\alpha_{n}\right)\left\|T_{\mu_{n}} x_{n}\right\|^{2} \\
&= \alpha_{n} \phi\left(u, x_{0}\right)+\left(1-\alpha_{n}\right) \phi\left(u, T_{\mu_{n}} x_{n}\right) \\
& \leq \alpha_{n} \phi\left(u, x_{0}\right)+\left(1-\alpha_{n}\right) \phi\left(u, x_{n}\right) .
\end{aligned}
$$

So, we have

$$
\begin{aligned}
& \left(1-\alpha_{n}\right)\left\{\phi\left(u, x_{n+1}\right)-\phi\left(u, x_{n}\right)\right\} \\
& \leq \alpha_{n}\left\{\phi\left(u, x_{0}\right)-\phi\left(u, x_{n+1}\right)\right\} \\
& \leq \alpha_{n} \phi\left(u, x_{0}\right) .
\end{aligned}
$$

Since $\lim _{n \rightarrow \infty} \alpha_{n}=0$, we obtain

$$
\lim _{n \rightarrow \infty}\left\{\phi\left(u, x_{n+1}\right)-\phi\left(u, x_{n}\right)\right\} \leq 0 .
$$

Therefore $\left\{\phi\left(u, x_{n}\right)\right\}$ is bounded and $\lim _{n \rightarrow \infty} \phi\left(u, x_{n}\right)$ exists. Then $\left\{x_{n}\right\}$ is also bounded. This implies that $\left\{T_{\mu_{n}} x_{n}\right\}$ is bounded. Since the interior of $F(\mathfrak{I})$ is nonempty, there exist $p \in F(\mathfrak{I})$ and $r>0$ such that

$$
p+r q \in F(\Im)
$$

whenever $\|q\| \leq 1$. By $\left(\phi_{2}\right)$, we have

$$
\begin{aligned}
\phi\left(u, x_{n}\right)= & \phi\left(u, x_{n+1}\right)+\phi\left(x_{n+1}, x_{n}\right) \\
& +2\left\langle u-x_{n+1}, J x_{n+1}-J x_{n}\right\rangle,
\end{aligned}
$$


for any $u \in F(\mathfrak{I})$. This implies

$$
\begin{gathered}
\left\langle x_{n+1}-u, J x_{n}-J x_{n+1}\right\rangle+\frac{1}{2} \phi\left(x_{n+1}, x_{n}\right) \\
=\frac{1}{2}\left(\phi\left(u, x_{n}\right)-\phi\left(u, x_{n+1}\right)\right) .
\end{gathered}
$$

Also, we have

$$
\begin{aligned}
\left\langle x_{n+1}-\right. & \left.p, J x_{n}-J x_{n+1}\right\rangle \\
= & \left\langle x_{n+1}-(p+r q)+r q, J x_{n}-J x_{n+1}\right\rangle \\
= & \left\langle x_{n+1}-(p+r q), J x_{n}-J x_{n+1}\right\rangle \\
& +r\left\langle q, J x_{n}-J x_{n+1}\right\rangle .
\end{aligned}
$$

On the other hand, by (24) and (25), we have that

$$
\phi\left(p+r q, x_{n+1}\right) \leq \phi\left(p+r q, x_{n}\right) .
$$

From (27), we get

$$
\begin{aligned}
0 \leq & \frac{1}{2}\left(\phi\left(p+r q, x_{n}\right)-\phi\left(p+r q, x_{n+1}\right)\right) \\
= & \left\langle x_{n+1}-(p+r q), J x_{n}-J x_{n+1}\right\rangle \\
& +\frac{1}{2} \phi\left(x_{n+1}, x_{n}\right) \\
= & \left\langle x_{n+1}-p, J x_{n}-J x_{n+1}\right\rangle \\
& -r\left\langle q, J x_{n}-J x_{n+1}\right\rangle+\frac{1}{2} \phi\left(x_{n+1}, x_{n}\right) .
\end{aligned}
$$

Then, by (27), we have

$$
\begin{aligned}
r\left\langle q, J x_{n}-J x_{n+1}\right\rangle \\
\quad \leq\left\langle x_{n+1}-p, J x_{n}-J x_{n+1}\right\rangle+\frac{1}{2} \phi\left(x_{n+1}, x_{n}\right) \\
\quad=\frac{1}{2}\left(\phi\left(p, x_{n}\right)-\phi\left(p, x_{n+1}\right)\right),
\end{aligned}
$$

for $p \in F(\mathfrak{I})$. Hence

$$
\left\langle q, J x_{n}-J x_{n+1}\right\rangle \leq \frac{1}{2 r}\left(\phi\left(p, x_{n}\right)-\phi\left(p, x_{n+1}\right)\right) .
$$

Since $q$ with $\|q\| \leq 1$ is arbitrary, by (24), we have

$$
\left\|J x_{n}-J x_{n+1}\right\| \leq \frac{1}{2 r}\left(\phi\left(p, x_{n}\right)-\phi\left(p, x_{n+1}\right)\right) .
$$

So, we have

$$
\begin{aligned}
& \left\|J x_{n+m}-J x_{n}\right\| \\
& =\| J x_{n+m}-J x_{n+m-1}+J x_{n+m-1} \\
& \quad-\cdots-J x_{n+1}+J x_{n+1}-J x_{n} \|
\end{aligned}
$$

$$
\begin{aligned}
& \leq \sum_{i=n}^{n+m-1}\left\|J x_{i}-J x_{i+1}\right\| \\
& \leq \frac{1}{2 r} \sum_{i=n}^{n+m-1}\left(\phi\left(p, x_{i}\right)-\phi\left(p, x_{i+1}\right)\right) \\
& =\frac{1}{2 r}\left(\phi\left(p, x_{n}\right)-\phi\left(p, x_{n+1}\right)\right) .
\end{aligned}
$$

We know that $\left\{\phi\left(p, x_{n}\right)\right\}$ converges. Hence, $\left\{J x_{n}\right\}$ is a Cauchy sequence. Since $E^{*}$ is complete, $\left\{J x_{n}\right\}$ converges strongly to some point in $E^{*}$. Since $E$ is uniformly convex, $E^{*}$ has a Fréchet differentiable norm. Then $J^{-1}$ is continuous on $E^{*}$. Hence $\left\{x_{n}\right\}$ converges strongly to some point $v$ in $C$.

Now, we show that $v \in F(\mathfrak{I})$, where $v=\lim _{n \rightarrow \infty} \Pi_{F(\mathfrak{\Im})} x_{n}$. By (33) and the convergence of $\left\{\phi\left(p, x_{n}\right)\right\}$, we have

$$
\lim _{n \rightarrow \infty}\left\|J x_{n}-J x_{n+1}\right\|=0 \text {. }
$$

Since $J^{-1}$ is uniformly norm-to-norm continuous on bounded sets, it follows that

$$
\lim _{n \rightarrow \infty}\left\|x_{n}-x_{n+1}\right\|=0
$$

Let $z_{n}=J^{-1}\left(\alpha_{n} J x_{0}+\left(1-\alpha_{n}\right) J T_{\mu_{n}} x_{n}\right)$. Then, we have

$$
\begin{aligned}
\| J z_{n} & -J T_{\mu_{n}} x_{n} \| \\
& =\left\|\alpha_{n} J x_{0}+\left(1-\alpha_{n}\right) J T_{\mu_{n}} x_{n}-J T_{\mu_{n}} x_{n}\right\| \\
& =\alpha_{n}\left\|J x_{0}-J T_{\mu_{n}} x_{n}\right\| .
\end{aligned}
$$

Since $\lim _{n \rightarrow \infty} \alpha_{n}=0$, we have

$$
\lim _{n \rightarrow \infty}\left\|J z_{n}-J T_{\mu_{n}} x_{n}\right\|=0
$$

Since $J^{-1}$ is uniformly norm-to-norm continuous on bounded sets, we get

$$
\lim _{n \rightarrow \infty}\left\|z_{n}-T_{\mu_{n}} x_{n}\right\|=0
$$

From $x_{n+1}=\Pi_{C} z_{n}$ and Lemma 4, we have

$$
\begin{aligned}
& \phi\left(T_{\mu_{n}} x_{n}, x_{n+1}\right)+\phi\left(x_{n+1}, z_{n}\right) \\
& \quad=\phi\left(T_{\mu_{n}} x_{n}, \Pi_{C} z_{n}\right)+\phi\left(\Pi_{C} z_{n}, z_{n}\right) \\
& \quad \leq \phi\left(T_{\mu_{n}} x_{n}, z_{n}\right) .
\end{aligned}
$$


Since

$$
\begin{aligned}
& \phi\left(T_{\mu_{n}} x_{n}, z_{n}\right) \\
&= \phi\left(T_{\mu_{n}} x_{n}, J^{-1}\left(\alpha_{n} J x_{0}+\left(1-\alpha_{n}\right) J T_{\mu_{n}} x_{n}\right)\right) \\
&=\left\|T_{\mu_{n}} x_{n}\right\|^{2}-2\left\langle T_{\mu_{n}} x_{n}, \alpha_{n} J x_{0}+\left(1-\alpha_{n}\right) J T_{\mu_{n}} x_{n}\right\rangle \\
&+\left\|\alpha_{n} J x_{0}+\left(1-\alpha_{n}\right) J T_{\mu_{n}} x_{n}\right\|^{2} \\
& \leq\left\|T_{\mu_{n}} x_{n}\right\|^{2}-2 \alpha_{n}\left\langle T_{\mu_{n}} x_{n}, J x_{0}\right\rangle \\
&-2\left(1-\alpha_{n}\right)\left\langle T_{\mu_{n}} x_{n}, J T_{\mu_{n}} x_{n}\right\rangle \\
&+\alpha_{n}\left\|x_{0}\right\|^{2}+\left(1-\alpha_{n}\right)\left\|T_{\mu_{n}} x_{n}\right\|^{2} \\
&= \alpha_{n} \phi\left(T_{\mu_{n}} x_{n}, x_{0}\right)+\left(1-\alpha_{n}\right) \phi\left(T_{\mu_{n}} x_{n}, T_{\mu_{n}} x_{n}\right) \\
&= \alpha_{n} \phi\left(T_{\mu_{n}} x_{n}, x_{0}\right)
\end{aligned}
$$

and $\lim _{n \rightarrow \infty} \alpha_{n}=0$, we have

$$
\lim _{n \rightarrow \infty} \phi\left(T_{\mu_{n}} x_{n}, z_{n}\right)=0
$$

From (40), we get

$$
\operatorname{Lim}_{n \rightarrow \infty} \phi\left(T_{\mu_{n}} x_{n}, x_{n+1}\right)=\lim _{n \rightarrow \infty} \phi\left(x_{n+1}, z_{n}\right)=0 .
$$

By Lemma 5, we obtain

$$
\lim _{n \rightarrow \infty}\left\|T_{\mu_{n}} x_{n}-x_{n+1}\right\|=\lim _{n \rightarrow \infty}\left\|x_{n+1}-z_{n}\right\|=0 .
$$

Since $\left\|x_{n}-T_{\mu_{n}} x_{n}\right\| \leq\left\|x_{n}-x_{n+1}\right\|+\left\|x_{n+1}-z_{n}\right\|+\left\|z_{n}-T_{\mu_{n}} x_{n}\right\|$, from (36), (39), and (44), we have

$$
\lim _{n \rightarrow \infty}\left\|x_{n}-T_{\mu_{n}} x_{n}\right\|=0 \text {. }
$$

From Lemma 7, we have $x_{n} \in F(\mathfrak{I})$. Since $F(\mathfrak{I})$ is closed and $\lim _{n \rightarrow \infty} x_{n}=v$, we have $v \in F(\mathfrak{I})$, where $v=$ $\lim _{n \rightarrow \infty} \Pi_{F(\Im)} x_{n}$.

We now establish a convergence theorem of modified Ishikawa type.

Theorem 9. Let $S$ be a left reversible semigroup and let $\mathfrak{\Im}=$ $\{T(s): s \in S\}$ be a representation of S as relatively nonexpansive mappings from a nonempty, closed, and convex subset $C$ of a uniformly convex and uniformly smooth Banach space $E$ into itself. Let $X$ be a subspace of $l^{\infty}(S)$ and let $\left\{\mu_{n}\right\}$ be an asymptotically left invariant sequence of means on $X$. Let $\left\{\alpha_{n}\right\}$ and $\left\{\beta_{n}\right\}$ be sequences of real numbers such that $\alpha_{n}, \beta_{n} \in(0,1)$ and $\lim _{n \rightarrow \infty} \alpha_{n}=0, \lim _{n \rightarrow \infty} \beta_{n}=1$. Let $\left\{x_{n}\right\}$ be a sequence generated by the following algorithm:

$$
\begin{gathered}
x_{0} \in C, \quad \text { chosen arbitrarily, } \\
y_{n}=J^{-1}\left(\beta_{n} J x_{n}+\left(1-\beta_{n}\right) J T_{\mu_{n}} x_{n}\right), \\
x_{n+1}=\Pi_{C} J^{-1}\left(\alpha_{n} J x_{n}+\left(1-\alpha_{n}\right) J T_{\mu_{n}} y_{n}\right), \quad \forall n \geq 0 .
\end{gathered}
$$

If the interior of $F(\Im)$ is nonempty, then $\left\{x_{n}\right\}$ converges strongly to some common fixed point $F(\mathfrak{\Im})$.

Proof. Firstly, we show that $\left\{x_{n}\right\}$ converges strongly in $C$.

From Lemma 3, we know $F(T)$ is closed and convex. So, we can define the generalized projection $\Pi_{C}$ onto $F(\Im)$. Let $u \in F(\mathfrak{I})$. From the definition of relatively nonexpansive and the convexity of $\|\cdot\|^{2}$, from (21), we have

$$
\begin{aligned}
\phi\left(u, y_{n}\right) & =\phi\left(u, J^{-1}\left(\beta_{n} J x_{n}+\left(1-\beta_{n}\right) J T_{\mu_{n}} x_{n}\right)\right) \\
& \leq \beta_{n} \phi\left(u, x_{n}\right)+\left(1-\beta_{n}\right) \phi\left(u, T_{\mu_{n}} x_{n}\right) \\
& \leq \phi\left(u, x_{n}\right),
\end{aligned}
$$

for all $u \in F(\mathfrak{I})$. From (47), we obtain

$$
\begin{aligned}
& \phi\left(u, x_{n+1}\right) \\
& \quad=\phi\left(u, \Pi_{C} J^{-1}\left(\alpha_{n} J x_{n}+\left(1-\alpha_{n}\right) J T_{\mu_{n}} y_{n}\right)\right) \\
& \leq \phi\left(u, J^{-1}\left(\alpha_{n} J x_{n}+\left(1-\alpha_{n}\right) J T_{\mu_{n}} y_{n}\right)\right) \\
& \quad \leq \alpha_{n} \phi\left(u, x_{n}\right)+\left(1-\alpha_{n}\right) \phi\left(u, T_{\mu_{n}} y_{n}\right) \\
& \leq \alpha_{n} \phi\left(u, x_{n}\right)+\left(1-\alpha_{n}\right) \phi\left(u, y_{n}\right) \\
& \leq \phi\left(u, x_{n}\right) .
\end{aligned}
$$

Hence, $\left\{\phi\left(u, x_{n}\right)\right\}$ is bounded and $\lim _{n \rightarrow \infty} \phi\left(u, x_{n}\right)$ exists. This implies that $\left\{x_{n}\right\},\left\{T_{\mu_{n}} x_{n}\right\}$, and $\left\{y_{n}\right\}$ are bounded. Since the interior of $F(\mathfrak{I})$ is nonempty, similar to the proof of Theorem 8, we obtain that $\left\{x_{n}\right\}$ converges strongly to $v$ in $C$.

Next, we show that $v \in F(\mathfrak{I})$, where $v=\lim _{n \rightarrow \infty} \Pi_{F(\mathfrak{I})} x_{n}$. Let

$$
z_{n}=J^{-1}\left(\alpha_{n} J x_{n}+\left(1-\alpha_{n}\right) J T_{\mu_{n}} y_{n}\right)
$$

From Lemma 4, we have

$$
\begin{aligned}
& \phi\left(x_{n}, x_{n+1}\right)+\phi\left(x_{n+1}, z_{n}\right) \\
& \quad=\phi\left(x_{n}, \Pi_{C} z_{n}\right)+\phi\left(\Pi_{C} z_{n}, z_{n}\right) \\
& \quad \leq \phi\left(x_{n}, z_{n}\right) .
\end{aligned}
$$

Also,

$$
\begin{aligned}
\phi\left(x_{n}, z_{n}\right) & =\phi\left(x_{n}, J^{-1}\left(\alpha_{n} J x_{n}+\left(1-\alpha_{n}\right) J T_{\mu_{n}} y_{n}\right)\right) \\
& \leq \alpha_{n} \phi\left(x_{n}, x_{n}\right)+\left(1-\alpha_{n}\right) \phi\left(x_{n}, T_{\mu_{n}} y_{n}\right) \\
& \leq \alpha_{n} \phi\left(x_{n}, x_{n}\right)+\left(1-\alpha_{n}\right) \phi\left(x_{n}, y_{n}\right) \\
& \leq \phi\left(x_{n}, y_{n}\right), \\
\left\|J x_{n}-J y_{n}\right\| & =\left\|J x_{n}-\left(\beta_{n} J x_{n}-\left(1-\beta_{n}\right) J T_{\mu_{n}} x_{n}\right)\right\| \\
& =\left(1-\beta_{n}\right)\left\|J x_{n}-J T_{\mu_{n}} x_{n}\right\| .
\end{aligned}
$$

From $\lim _{n \rightarrow \infty} \beta_{n}=1$ and (52), we have

$$
\lim _{n \rightarrow \infty}\left\|J x_{n}-J y_{n}\right\|=0 \text {. }
$$


Since $J^{-1}$ is uniformly norm-to-norm continuous, we obtain

$$
\lim _{n \rightarrow \infty}\left\|x_{n}-y_{n}\right\|=0
$$

Hence,

$$
\begin{aligned}
\phi\left(x_{n}, y_{n}\right)= & \left\|x_{n}\right\|^{2}-2\left\langle x_{n}, J y_{n}\right\rangle+\left\|y_{n}\right\|^{2} \\
= & \left\|x_{n}\right\|^{2}-2\left\langle x_{n}, J y_{n}-J x_{n}\right\rangle \\
& -2\left\langle x_{n}, J x_{n}\right\rangle+\left\|y_{n}\right\|^{2} \\
\leq & \left\|y_{n}\right\|^{2}-\left\|x_{n}\right\|^{2} \\
& +2\left\|x_{n}\right\|\left\|J y_{n}-J x_{n}\right\| \\
\leq & \left\|y_{n}-x_{n}\right\|\left(\left\|y_{n}\right\|+\left\|x_{n}\right\|\right) \\
& +2\left\|x_{n}\right\|\left\|J y_{n}-J x_{n}\right\| .
\end{aligned}
$$

By (53) and (54), we have

$$
\lim _{n \rightarrow \infty} \phi\left(x_{n}, y_{n}\right)=0
$$

From (50) and (51), we obtain

$$
\lim _{n \rightarrow \infty} \phi\left(x_{n}, x_{n+1}\right)=\lim _{n \rightarrow \infty} \phi\left(x_{n}, z_{n}\right)=0 .
$$

From Lemma 5, we get

$$
\lim _{n \rightarrow \infty}\left\|x_{n}-x_{n+1}\right\|=\lim _{n \rightarrow \infty}\left\|x_{n}-z_{n}\right\|=0 .
$$

Since

$$
\begin{aligned}
\left\|J z_{n}-J T_{\mu_{n}} y_{n}\right\| & =\left\|\alpha_{n} J x_{n}+\left(1-\alpha_{n}\right) J T_{\mu_{n}} y_{n}-J T_{\mu_{n}} y_{n}\right\| \\
& =\alpha_{n}\left\|J x_{n}-J T_{\mu_{n}} x_{n}\right\|
\end{aligned}
$$

and $\lim _{n \rightarrow \infty} \alpha_{n}=0$, we have

$$
\lim _{n \rightarrow \infty}\left\|J z_{n}-J T_{\mu_{n}} y_{n}\right\|=0
$$

Since $J^{-1}$ is uniformly norm-to-norm continuous, we obtain

$$
\lim _{n \rightarrow \infty}\left\|z_{n}-T_{\mu_{n}} y_{n}\right\|=0
$$

Since $\lim _{n \rightarrow \infty}\left\|x_{n}-z_{n}\right\|=0$ and $J$ is uniformly norm-to-norm continuous,

$$
\lim _{n \rightarrow \infty}\left\|J x_{n}-J z_{n}\right\|=0
$$

By (46) and (49), we have

$$
\begin{aligned}
& J T_{\mu_{n}} x_{n}=\frac{1}{1-\beta_{n}}\left(J y_{n}-\beta_{n} J x_{n}\right), \\
& J T_{\mu_{n}} y_{n}=\frac{1}{1-\alpha_{n}}\left(J z_{n}-\alpha_{n} J x_{n}\right) .
\end{aligned}
$$

From (63), we obtain

$$
\begin{aligned}
\left\|J T_{\mu_{n}} x_{n}-J T_{\mu_{n}} y_{n}\right\| \\
=\| \frac{1}{1-\beta_{n}}\left(J y_{n}-\beta_{n} J x_{n}\right) \\
\quad-\frac{1}{1-\alpha_{n}}\left(J z_{n}-\alpha_{n} J x_{n}\right) \| \\
=\| J y_{n}+\frac{\beta_{n}}{1-\beta_{n}}\left(J y_{n}-J x_{n}\right) \\
\quad-\left(J z_{n}+\frac{\alpha_{n}}{1-\alpha_{n}}\left(J z_{n}-J x_{n}\right)\right) \| \\
\leq\left\|J y_{n}-J x_{n}\right\|+\left\|J x_{n}-J z_{n}\right\| \\
\quad+\frac{\beta_{n}}{1-\beta_{n}}\left\|J y_{n}-J x_{n}\right\|+\frac{\alpha_{n}}{1-\alpha_{n}}\left\|J z_{n}-J x_{n}\right\| \\
=\frac{1}{1-\alpha_{n}}\left\|J z_{n}-J x_{n}\right\|+\frac{1}{1-\beta_{n}}\left\|J y_{n}-J x_{n}\right\| .
\end{aligned}
$$

Combining (53), (62), and (64), we get

$$
\lim _{n \rightarrow \infty}\left\|J T_{\mu_{n}} x_{n}-J T_{\mu_{n}} y_{n}\right\|=0 .
$$

Since $J^{-1}$ is uniformly norm-to-norm continuous, we have

$$
\lim _{n \rightarrow \infty}\left\|T_{\mu_{n}} x_{n}-T_{\mu_{n}} y_{n}\right\|=0 \text {. }
$$

Since

$$
\begin{gathered}
\left\|x_{n}-T_{\mu_{n}} x_{n}\right\| \leq\left\|x_{n}-z_{n}\right\|+\left\|z_{n}-T_{\mu_{n}} y_{n}\right\| \\
+\left\|T_{\mu_{n}} y_{n}-T_{\mu_{n}} x_{n}\right\|,
\end{gathered}
$$

therefore, by (58), (61), (66), and (67), we obtain

$$
\lim _{n \rightarrow \infty}\left\|x_{n}-T_{\mu_{n}} x_{n}\right\|=0 \text {. }
$$

From Lemma 7, we have $x_{n} \in F(\mathfrak{I})$. Since $F(\mathfrak{I})$ is closed and $\lim _{n \rightarrow \infty} x_{n}=v$, we have $v \in F(\mathfrak{I})$, where $v=$ $\lim _{n \rightarrow \infty} \prod_{F(\mathfrak{I})} x_{n}$.

If we set $\beta_{n}=1$, then the iteration (46) reduces modified Mann type. Hence we obtain the following corollary.

Corollary 10. Let $S$ be a left reversible semigroup and let $\mathfrak{I}=\{T(s): s \in S\}$ be a representation of $S$ as relatively nonexpansive mappings from a nonempty, closed, and convex subset $C$ of a uniformly convex and uniformly smooth Banach space $E$ into itself. Let $X$ be a subspace of $l^{\infty}(S)$ and let $\left\{\mu_{n}\right\}$ be an asymptotically left invariant sequence of means on $X$. Let $\left\{\alpha_{n}\right\}$ be a sequence of real number such that $\alpha_{n} \in(0,1)$ and $\lim _{n \rightarrow \infty} \alpha_{n}=0$. Let $\left\{x_{n}\right\}$ be a sequence generated by the following algorithm:

$$
\begin{gathered}
x_{0} \in C, \quad \text { chosen arbitrarily, } \\
x_{n+1}=\Pi_{C} J^{-1}\left(\alpha_{n} J x_{n}+\left(1-\alpha_{n}\right) J T_{\mu_{n}} x_{n}\right), \quad \forall n \geq 0 .
\end{gathered}
$$

If the interior of $F(\Im)$ is nonempty, then $\left\{x_{n}\right\}$ converges strongly to some common fixed point $F(\mathfrak{I})$. 
In a Hilbert space, $J$ is the identity operator. Theorems 8 and 9 reduce to the following.

Corollary 11. Let $S$ be a left reversible semigroup and let $\mathfrak{J}=\{T(s): s \in S\}$ be a representation of $S$ as relatively nonexpansive mappings from a nonempty, closed, and convex subset $C$ of a Hilbert space $H$ into itself. Let $X$ be a subspace of $l^{\infty}(S)$ and let $\left\{\mu_{n}\right\}$ be an asymptotically left invariant sequence of means on $X$. Let $\left\{\alpha_{n}\right\}$ be a sequence in $(0,1)$ such that $\lim _{n \rightarrow \infty} \alpha_{n}=0$. Let $\left\{x_{n}\right\}$ be a sequence generated by the following algorithm:

$$
\begin{gathered}
x_{0} \in C, \quad \text { chosen arbitrarily, } \\
x_{n+1}=P_{C}\left(\alpha_{n} x_{0}+\left(1-\alpha_{n}\right) T_{\mu_{n}} x_{n}\right), \quad \forall n \geq 0 .
\end{gathered}
$$

If the interior of $F(\Im)$ is nonempty, then $\left\{x_{n}\right\}$ converges strongly to some common fixed point $F(\Im)$, where $P_{C}$ is a metric projection.

Corollary 12. Let $S$ be a left reversible semigroup and let $\mathfrak{J}=\{T(s): s \in S\}$ be a representation of $S$ as relatively nonexpansive mappings from a nonempty, closed, and convex subset $C$ of a Hilbert space $H$ into itself. Let $X$ be a subspace of $l^{\infty}(S)$ and let $\left\{\mu_{n}\right\}$ be an asymptotically left invariant sequence of means on $X$. Let $\left\{\alpha_{n}\right\}$ and $\left\{\beta_{n}\right\}$ be sequences of real numbers such that $\alpha_{n}, \beta_{n} \in(0,1)$ and $\lim _{n \rightarrow \infty} \alpha_{n}=0, \lim _{n \rightarrow \infty} \beta_{n}=1$. Let $\left\{x_{n}\right\}$ be a sequence generated by the following algorithm:

$$
\begin{gathered}
x_{0} \in C, \quad \text { chosen arbitrarily, } \\
y_{n}=\beta_{n} x_{n}+\left(1-\beta_{n}\right) T_{\mu_{n}} x_{n}, \\
x_{n+1}=P_{C}\left(\alpha_{n} x_{n}+\left(1-\alpha_{n}\right) T_{\mu_{n}} y_{n}\right), \quad \forall n \geq 0 .
\end{gathered}
$$

If the interior of $F(\Im)$ is nonempty, then $\left\{x_{n}\right\}$ converges strongly to some common fixed point $F(\mathfrak{I})$, where $P_{C}$ is a metric projection.

\section{Conflict of Interests}

The author declares that there is no conflict of interests regarding the publication of this paper.

\section{Acknowledgments}

The author would like to thank Professor Anthony To-Ming Lau and Professor Jong Kyu Kim for their helpful suggestions. Also, special thanks are due to the referee for his/her deep insight which improved the paper. This work was supported by Kyungnam University Foundation Grant, 2013.

\section{References}

[1] B. Halpern, "Fixed points of nonexpanding maps," Bulletin of the American Mathematical Society, vol. 73, pp. 957-961, 1967.

[2] W. R. Mann, "Mean value methods in iteration," Proceedings of the American Mathematical Society, vol. 4, pp. 506-510, 1953.

[3] S. Ishikawa, "Fixed points by a new iteration method," Proceedings of the American Mathematical Society, vol. 44, pp. 147-150, 1974.
[4] A. T. Lau, H. Miyake, and W. Takahashi, "Approximation of fixed points for amenable semigroups of nonexpansive mappings in Banach spaces," Nonlinear Analysis: Theory, Methods \& Applications, vol. 67, no. 4, pp. 1211-1225, 2007.

[5] S. Reich, "A weak convergence theorem for the alternating method with Bregman distance," in Theory and Applications of Nonlinear Operators of Accretive and Monotone Type, A. G. Kartsatos, Ed., pp. 313-318, Marcel Dekker, New York, NY, USA, 1996.

[6] D. Butnariu, S. Reich, and A. J. Zaslavski, "Asymptotic behavior of relatively nonexpansive operators in Banach spaces," Journal of Applied Analysis, vol. 7, no. 2, pp. 151-174, 2001.

[7] D. Butnariu, S. Reich, and A. J. Zaslavski, "Weak convergence of orbits of nonlinear operators in reflexive Banach spaces," Numerical Functional Analysis and Optimization, vol. 24, no. 56, pp. 489-508, 2003.

[8] Y. Censor and S. Reich, "Iterations of paracontractions and firmly nonexpansive operators with applications to feasibility and optimization," Optimization, vol. 37, no. 4, pp. 323-339, 1996.

[9] S. Matsushita and W. Takahashi, "A strong convergence theorem for relatively nonexpansive mappings in a Banach space," Journal of Approximation Theory, vol. 134, no. 2, pp. 257-266, 2005.

[10] K. S. Kim, "Convergence of a hybrid algorithm for a reversible semigroup of nonlinear operators in Banach spaces," Nonlinear Analysis: Theory, Methods \& Applications, vol. 73, no. 10, pp. 3413-3419, 2010.

[11] W. Takahashi, Convex Analysis and Approximation Fixed Points, Yokohama Publishers, 2000, (Japanese).

[12] Y. I. Alber, "Metric and generalized projection operators in Banach spaces: properties and applications," in Theory and Applications of Nonlinear Operators of Accretive and Monotone Type, A.G. Kartsatos, Ed., vol. 178, pp. 15-50, Marcel Dekker, New York, NY, USA, 1996.

[13] Y. I. Alber and S. Reich, "An iterative method for solving a class of nonlinear operator equations in Banach spaces," Panamerican Mathematical Journal, vol. 4, no. 2, pp. 39-54, 1994.

[14] I. Cioranescu, Geometry of Banach Spaces, Duality Mapping and Nonlinear Problems, Kluwer Academic, Amsterdam, The Netherlands, 1990.

[15] J. I. Kang, "Fixed points of non-expansive mappings associated with invariant means in a Banach space," Nonlinear Analysis: Theory, Methods \& Applications, vol. 68, no. 11, pp. 3316-3324, 2008.

[16] K. S. Kim, "Ergodic theorems for reversible semigroups of nonlinear operators," Journal of Nonlinear and Convex Analysis, vol. 13, no. 1, pp. 85-95, 2012.

[17] A. T. Lau, "Invariant means and fixed point properties of semigroup of nonexpansive mappings," Taiwanese Journal of Mathematics, vol. 12, no. 6, pp. 1525-1542, 2008.

[18] A. T. M. Lau, "Semigroup of nonexpansive mappings on a Hilbert space," Journal of Mathematical Analysis and Applications, vol. 105, no. 2, pp. 514-522, 1985.

[19] A. T. M. Lau and W. Takahashi, "Invariant means and fixed point properties for non-expansive representations of topological semigroups," Topological Methods in Nonlinear Analysis, vol. 5, no. 1, pp. 39-57, 1995.

[20] M. M. Day, “Amenable semigroups," Illinois Journal of Mathematics, vol. 1, pp. 509-544, 1957. 
[21] J. I. Kang, "Fixed point set of semigroups of non-expansive mappings and amenability," Journal of Mathematical Analysis and Applications, vol. 341, no. 2, pp. 1445-1456, 2008.

[22] A. T. Lau, N. Shioji, and W. Takahashi, "Existence of nonexpansive retractions for amenable semigroups of nonexpansive mappings and nonlinear ergodic theorems in Banach spaces," Journal of Functional Analysis, vol. 161, no. 1, pp. 62-75, 1999.

[23] R. D. Holmes and A. T. Lau, "Non-expansive actions of topological semigroups and fixed points," Journal of the London Mathematical Society, vol. 5, no. 2, pp. 330-336, 1972.

[24] K. S. Kim, "Nonlinear ergodic theorems of nonexpansive type mappings," Journal of Mathematical Analysis and Applications, vol. 358, no. 2, pp. 261-272, 2009.

[25] A. T.-M. Lau, "Invariant means on almost periodic functions and fixed point properties," Rocky Mountain Journal of Mathematics, vol. 3, pp. 69-76, 1973.

[26] A. T.-M. Lau and P. F. Mah, "Fixed point property for Banach algebras associated to locally compact groups," Journal of Functional Analysis, vol. 258, no. 2, pp. 357-372, 2010.

[27] A. T. M. Lau and W. Takahashi, "Weak convergence and nonlinear ergodic theorems for reversible semigroups of nonexpansive mappings," Pacific Journal of Mathematics, vol. 126, no. 2, pp. 277-294, 1987.

[28] A. T. Lau and Y. Zhang, "Fixed point properties of semigroups of non-expansive mappings," Journal of Functional Analysis, vol. 254, no. 10, pp. 2534-2554, 2008.

[29] N. Hirano, K. Kido, and W. Takahashi, "Nonexpansive retractions and nonlinear ergodic theorems in Banach spaces," Nonlinear Analysis: Theory, Methods \& Applications, vol. 12, no. 11, pp. 1269-1281, 1988.

[30] S. Saeidi, "Existence of ergodic retractions for semigroups in Banach spaces," Nonlinear Analysis: Theory, Methods \& Applications, vol. 69, no. 10, pp. 3417-3422, 2008.

[31] W. Takahashi, "A nonlinear ergodic theorem for an amenable semigroup of nonexpansive mappings in a Hilbert space," Proceedings of the American Mathematical Society, vol. 81, no. 2, pp. 253-256, 1981.

[32] S. Kamimura and W. Takahashi, "Strong convergence of a proximal-type algorithm in a Banach space," SIAM Journal on Optimization, vol. 13, no. 3, pp. 938-945, 2002.

[33] S. Saeidi, "Strong convergence of Browder's type iterations for left amenable semigroups of Lipschitzian mappings in BANach spaces," Journal of Fixed Point Theory and Applications, vol. 5, no. 1, pp. 93-103, 2009.

[34] F. Kohsaka and W. Takahashi, "Existence and approximation of fixed points of firmly nonexpansive-type mappings in Banach spaces," SIAM Journal on Optimization, vol. 19, no. 2, pp. 824$835,2008$.

[35] F. Kohsaka and W. Takahashi, "Fixed point theorems for a class of nonlinear mappings related to maximal monotone operators in Banach spaces," Archiv der Mathematik, vol. 91, no. 2, pp. 166$177,2008$.

[36] W. Nilsrakoo and S. Saejung, "Strong convergence theorems by Halpern-Mann iterations for relatively nonexpansive mappings in Banach spaces," Applied Mathematics and Computation, vol. 217, no. 14, pp. 6577-6586, 2011. 


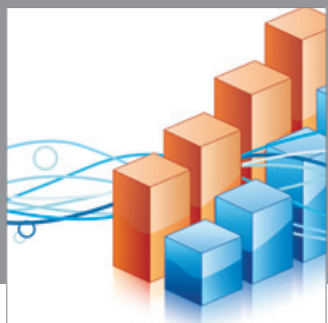

Advances in

Operations Research

mansans

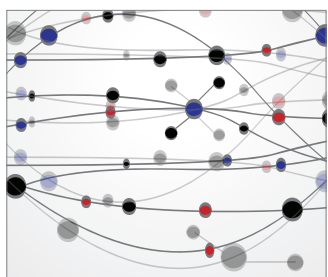

The Scientific World Journal
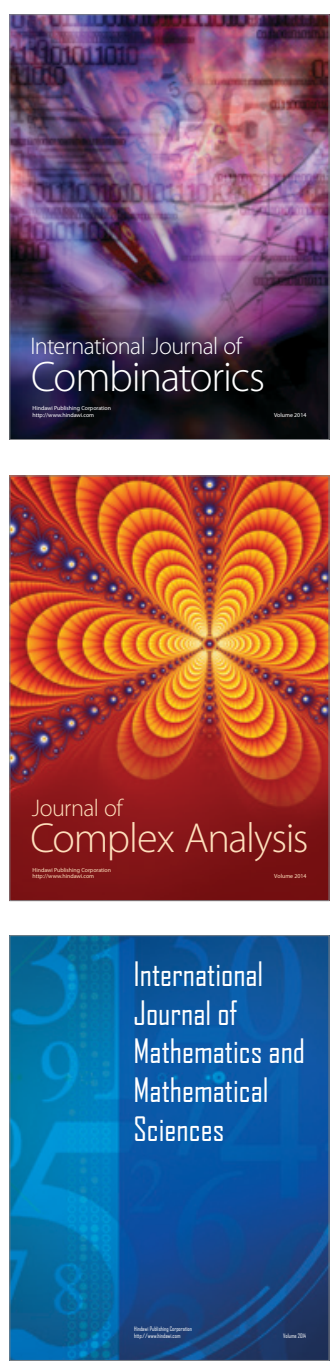
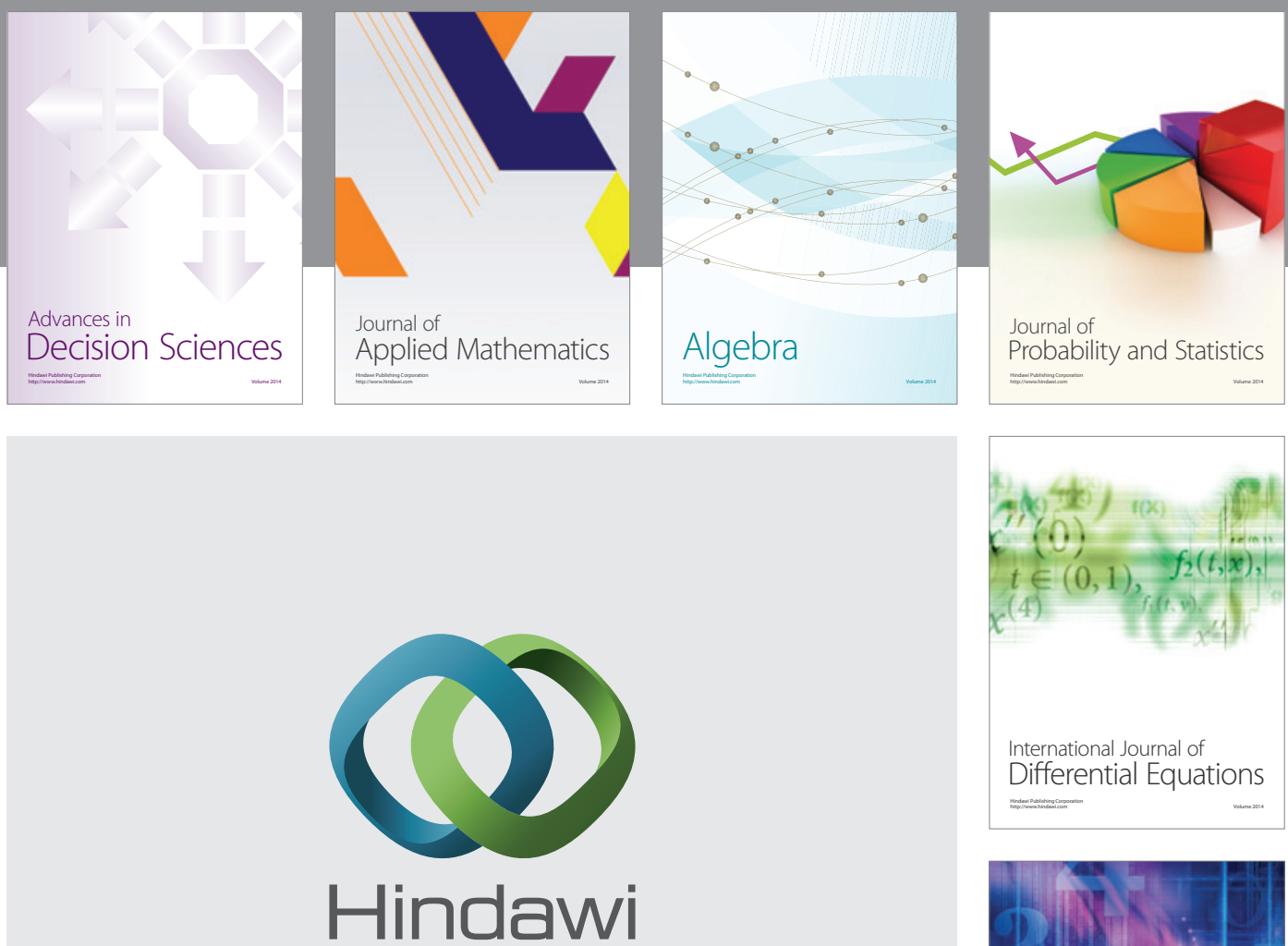

Submit your manuscripts at http://www.hindawi.com
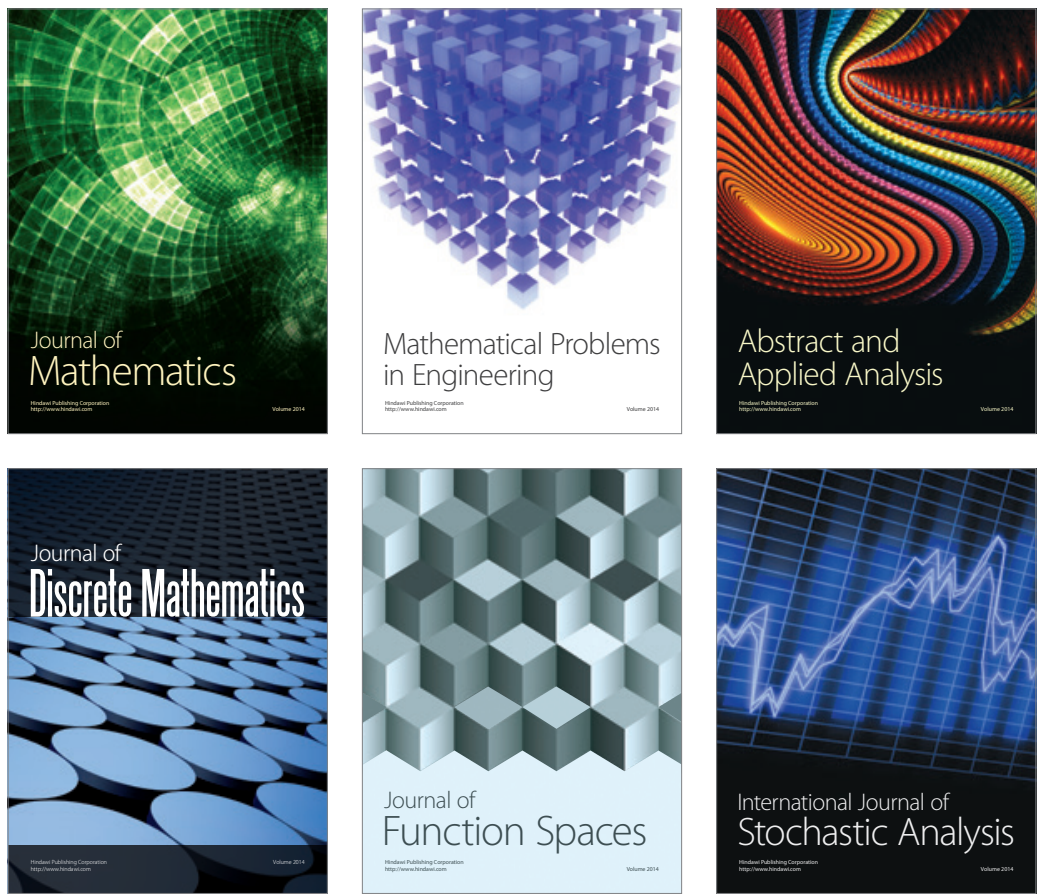

Journal of

Function Spaces

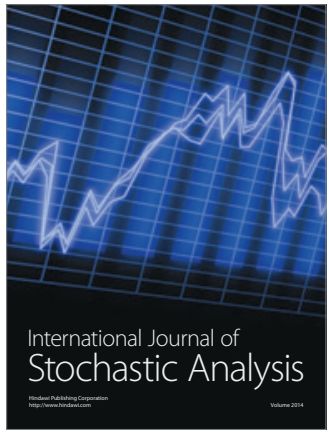

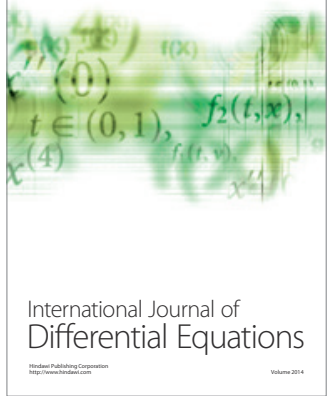
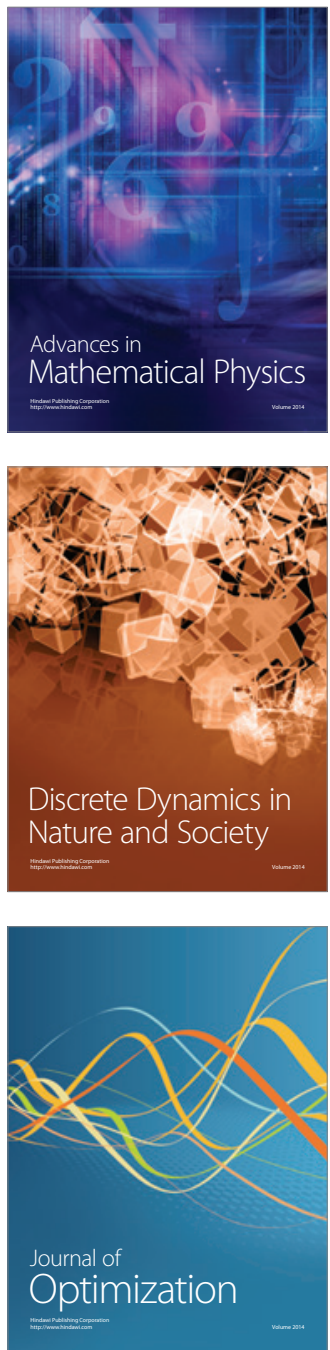